\title{
BMJ Open Net survival differences of breast cancer between stages at diagnosis and age groups in the east coast region of West Malaysia: a retrospective cohort study
}

\author{
Tengku Muhammad Hanis (D) , ${ }^{1}$ Najib Majdi Yaacob, ${ }^{1}$ Suhaily Mohd Hairon, ${ }^{2}$ \\ Sarimah Abdullah ${ }^{1}$
}

To cite: Hanis TM, Yaacob NM, Mohd Hairon S, et al. Net survival differences of breast cancer between stages at diagnosis and age groups in the east coast region of West Malaysia: a retrospective cohort study. BMJ Open 2021;11:e043642. doi:10.1136/ bmjopen-2020-043642

- Prepublication history for this paper is available online. To view these files, please visit the journal online (http://dx.doi. org/10.1136/bmjopen-2020043642).

Received 10 August 2020 Revised 08 February 2021 Accepted 01 April 2021

A) Check for updates

(c) Author(s) (or their employer(s)) 2021. Re-use permitted under CC BY-NC. No commercial re-use. See rights and permissions. Published by BMJ.

${ }^{1}$ Unit of Biostatistics and Research Methodology, School of Medical Sciences, Universiti Sains Malaysia - Kampus Kesihatan, Kubang Kerian, Malaysia

${ }^{2}$ Department of Community Medicine, School of Medical Sciences, Universiti Sains Malaysia - Kampus Kesihatan, Kubang Kerian, Malaysia

Correspondence to Dr Najib Majdi Yaacob; najibmy@usm.my

\section{ABSTRACT}

Objective Estimation of the net survival of breast cancer helps in assessing breast cancer burden at a population level. Thus, this study aims to estimate the net survival of breast cancer at different cancer staging and age at diagnosis in the east coast region of West Malaysia.

Setting Kelantan, Malaysia.

Participants All breast cancer cases diagnosed in 2007 and 2011 identified from Kelantan Cancer Registry. Design This retrospective cohort study used a relative survival approach to estimate the net survival of patients with breast cancer. Thus, two data were needed; breast cancer data from Kelantan Cancer Registry and general population mortality data for Kelantan population.

Primary and secondary outcome measures Net survival according to stage and age group at diagnosis at 1,3 and 5 years following diagnosis.

Results The highest net survival was observed among stage I and II breast cancer cases, while the lowest net survival was observed among stage IV breast cancer cases. In term of age at diagnosis, breast cancer cases aged 65 and older had the best net survival compared with the other age groups.

Conclusion The age at diagnosis had a minimal impact on the net survival compared with the stage at diagnosis. The finding of this study is applicable to other populations with similar breast cancer profile.

\section{INTRODUCTION}

Breast cancer is the most common cancer and the leading cause of cancer-related death among women globally. ${ }^{1}$ In the Asia region, the incidence of breast cancer had increased at least moderately in the Eastern and Southeastern region over the last two decades. ${ }^{2}$ Several studies have suggested that the increased incidences of breast cancer in Asia are due to factors such as economic growth and adoption of a more westernised lifestyle including no breastfeeding, reduced parity and increased animal fat consumption. ${ }^{3}{ }^{4}$ However, the risk of developing breast cancer in Malaysia is still lower compared with the USA and Europe, which is 1 in 19 and 1 in
Strengths and limitations of this study

- This population-based study used state cancer registry data to describe the net survival of breast cancer in the east coast region of West Malaysia.

- The use of relative survival approach to estimate the net survival is considered as a standard practice for a population-based study.

- This study expanded an abridged life table of the general population mortality data into a complete life table to estimate the net survival due to unavailability of a complete life table.

- The use of different method to expand the mortality data leading to a lack of standardisation in this research area.

- This study lacked socioeconomic, sociodemographic and clinical information which may further explain our finding.

8, respectively. ${ }^{5}$ In term of breast cancer survival, a 5-year relative survival between 2005 and 2009 in Malaysia was $67.8 \%$, while other Asian countries such South Korea $(82.7 \%)$, Indonesia $(77.7 \%)$ and Thailand $(71.3 \%)$ had a better survival. ${ }^{6}$ Breast cancer staging and age are important prognostic factors of breast cancer. Early-stage patients with breast cancer are expected to have better survival compared with those diagnosed at a later stage. ${ }^{7}$ Several studies considered age as an important prognostic factor of breast cancer, ${ }^{8-10}$ although several Malaysian studies did find it otherwise. ${ }^{11-13}$ There is a need to provide more information on breast cancer survival, generally in the Asia Pacific region and especially in Malaysia as it will help in planning effective public health management and control of the disease.

Net survival (NS) is a hypothetical measure in which the only possible cause of death is the disease of interest. ${ }^{14}{ }^{15} \mathrm{NS}$ aims to reflect the cancer burden and provides an accurate 
comparison between populations or time periods. ${ }^{16}$ There are two approaches for survival analysis; a causespecific survival and a relative survival. The main difference between these two methods is that the former need information on the exact cause of death, while the latter does not. ${ }^{17}$ The relative survival approach is a common practice for a cancer registry study since this approach is corrected by the population mortality. Thus, this approach provides a better comparison between populations or subpopulations. ${ }^{18}$ Additionally, information on cause-specific deaths are not reliable and poorly recorded in most cancer registries. Consequently, a slight misclassification of the cause of death may lead to a large difference in the NS estimate. ${ }^{19}$ The purpose of this study is to determine the NS of breast cancer in the east-coast region of West Malaysia, according to cancer staging and age at diagnosis.

\section{MATERIALS AND METHODS}

\section{Study designs and population}

Kelantan is one of the three states located in the east coast region of West Malaysia. This retrospective cohort study needed two data for the relative survival approach; the observed population, which is the breast cancer data, and the expected population, which is the general population mortality data.

Data of patients with breast cancer were obtained from the Kelantan Cancer Registry in non-communicable disease unit, Kelantan State Health Department. The Kelantan Cancer Registry includes all cancer cases notified by all hospitals in Kelantan, Malaysia. The International Classification of Diseases for Oncology codes C50 series was used to diagnosed all breast cancer cases. Details of data collection, registration procedure and quality control of breast cancer data collected by Kelantan Cancer Registry were described in the Malaysian national cancer registry report. ${ }^{20}$ This study included all Kelantan female patients with breast cancer diagnosed between 1 January 2007 and 31 December 2011. All breast cancer cases had a follow-up record until 31 December 2016. At the time of this study was carried out, the registry only had a complete breast cancer records up to 31 December 2011, and each had a follow-up record until 31 December 2016. Out of 598 cases in the registry, 49 cases had a missing breast cancer staging, thus excluded from the analysis. Variables such as age at diagnosis, ethnicity, morphology and cancer staging were assessed during the data collection process. Additionally, the tumour, node, metastasis classification system was used to classified the breast cancer staging in the registry.

The general population mortality data for Kelantan population was used. The data were obtained from the Department of Statistics, Malaysia (DOSM) between 2007 and 2016. The general population mortality data should be in the form of a complete life table. However, the data available from the DOSM were in the form of an abridged life table. Details of data collection and methods used in the construction of abridged life tables by the DOSM were described in their reports. ${ }^{21-23}$ This study expanded the abridged life table into a complete life table.

\section{Patient and public involvement}

Patients were not involved in the design and development of this study. This study used secondary data obtained from a state registry and DOSM. Thus, there is no patient involved in the recruitment and conduct of the study. Patients were not informed of the study result. However, a final report of this study was submitted to the Human Research Ethics Committee, Universiti Sains Malaysia and Medical Research and Ethics Committee, Ministry of Health Malaysia for the closure of this study.

\section{Statistical analysis and software}

The expansion of the abridged life table of the Kelantan general population mortality data was done using the MORTPAK software V.4.3. ${ }^{24}$ R V.4.0. $2^{25}$ was used for data cleaning and management, descriptive statistics, and the estimation of the NS rates.

\section{Descriptive statistics}

Data cleaning and data exploration were done to identify any missing values. Categorical variables were presented in frequency and percentage, while numerical variables were presented in mean and SD. However, the survival time was presented in range, minimum value, maximum value, median and IQR.

\section{Expanding abridged life table}

The abridged life tables of the Kelantan general population mortality were expanded into the complete life tables using the UNABR application in the MORTPAK software. The UNABR application used the Heligman-Pollard model for this expansion. The variant of the model used in the UNABR application was:

$$
q_{x}=A^{(x+B)^{C}}+D e^{-E(\ln x-\ln F)^{2}}+\frac{G H^{x}}{1+G H^{x}}
$$

where ${ }_{1} q_{x}$ denotes the probability of dying at aged $\mathrm{x}$ within a year, and $\mathrm{A}, \mathrm{B}, \mathrm{C}, \mathrm{D}, \mathrm{E}, \mathrm{F}, \mathrm{G}$ and $\mathrm{H}$ were the parameters to be estimated. Several studies had agreed that the Heligman-Pollard model fits the Malaysian population considerably well. ${ }^{26-28}$ Two variables needed for the UNABR application were age and probability of dying between age $\mathrm{x}$ and age $\mathrm{x}+\mathrm{n}$ from the abridged life tables of Kelantan population mortality data. A complete life table produced from this application included variables; age in the yearly interval, central mortality rate between age $\mathrm{x}$ and age $\mathrm{x}+1$, probability of dying between age $\mathrm{x}$ and age $\mathrm{x}+1$, survivors at exact age $\mathrm{x}$ and life expectancy.

\section{Net survival}

The NS in the relative survival approach is defined as the ratio of overall survival of an observed population to the overall survival of an expected population in which there is no event of interest ${ }^{2930}$ :

$$
N S=\frac{S_{O}}{S_{E}} \times 100
$$


where $\mathrm{S}_{\mathrm{o}}$ denotes the overall survival in the observed population and $\mathrm{S}_{\mathrm{E}}$ is the overall survival in the expected population. Each of the individual in the observed population and the expected population was matched by age, sex and mortality year. The estimation of the NS through Pohar-Perme estimator was done using relsurv package in $\mathrm{R}$ software. ${ }^{31}$ Pohar-Perme estimator was proposed in $2012,{ }^{32} 33$ and it is relatively recent compared with the other available estimators such as Ederer I, Ederer II and Hakulinen. However, Pohar-Perme estimator has been proved to produce an unbiased estimate of the NS compared with other estimators. ${ }^{30} 3234$

\section{RESULTS}

\section{Profile of breast cancer}

After exclusion of 49 breast cancer cases with missing cancer staging, 549 cases were analysed. The overall mean age at diagnosis of patients with breast cancer in
Kelantan, Malaysia, was 50.4 years. The mean age at diagnosis of patients with breast cancer for each stage was not much different, ranging from 49.5 to 50.4 years. Majority of breast cancer cases overall and for each stage were Malay, followed by Chinese. Most of patients with breast cancer in this study were diagnosed in stage I (29.7\%) and stage II (29.3\%), while stage III and stage IV constituted $16.4 \%$ and $24.6 \%$, respectively, out of 549 patients. Table 1 shows the characteristics of patients with breast cancer according to the stage at diagnosis in Kelantan, Malaysia. Additionally, about $36.4 \%$ of patients with breast cancer in Kelantan, Malaysia were between the ages of 45 and $54,30.2 \%$ were between 15 and $44,20.6 \%$ were between $55.64 \%$, and the remaining $12.8 \%$ were aged 65 and older at the time of diagnosis. Further details of the characteristics of patients with breast cancer in Kelantan, Malaysia according to age groups are presented in table 2. The maximum survival time of patients with breast cancer

Table 1 Characteristic of patients with breast cancer in according to stage at diagnosis in Kelantan, Malaysia ( $\mathrm{n}=549$ )

\begin{tabular}{|c|c|c|c|c|c|c|c|}
\hline \multirow[b]{2}{*}{ Variables } & \multicolumn{3}{|l|}{ Overall } & \multicolumn{4}{|l|}{ Stages } \\
\hline & $\begin{array}{l}\text { Died } \\
\text { n (\%) }\end{array}$ & $\begin{array}{l}\text { Censored } \\
\mathrm{n}(\%)\end{array}$ & $\begin{array}{l}\text { Total } \\
\text { n (\%) }\end{array}$ & $\begin{array}{l}\text { Stage I } \\
\text { n (\%) }\end{array}$ & $\begin{array}{l}\text { Stage II } \\
\text { n (\%) }\end{array}$ & $\begin{array}{l}\text { Stage III } \\
\text { n (\%) }\end{array}$ & $\begin{array}{l}\text { Stage IV } \\
\mathrm{n}(\%)\end{array}$ \\
\hline Survival time (years)† & $(1.1)(2.2)$ & $7.2(2.4)$ & $5.4(6.2)$ & $6.0(5.1)$ & $6.5(2.5)$ & $4.7(5.2)$ & $0.6(2.5)$ \\
\hline Age at diagnosis (years) $\ddagger$ & $49.8(10.9)$ & $51.0(11.5)$ & $50.4(11.2)$ & $50.3(11.5)$ & $51.0(11.9)$ & $49.5(10.6)$ & $50.4(10.7)$ \\
\hline Malay & $240(93.4)$ & $231(79.1)$ & $471(85.8)$ & $144(88.3)$ & $125(77.6)$ & 80 (88.9) & $122(90.4)$ \\
\hline Chinese & $15(5.8)$ & $50(17.1)$ & $65(11.8)$ & $15(9.2)$ & $30(18.6)$ & $9(10.0)$ & $11(8.1)$ \\
\hline Indian & $1(0.4)$ & $4(1.4)$ & $5(0.9)$ & $1(0.6)$ & $3(1.9)$ & $0(0.0)$ & $1(0.7)$ \\
\hline Others & $1(0.4)$ & $7(2.4)$ & $8(1.5)$ & $3(1.8)$ & $3(1.9)$ & $1(1.1)$ & $1(0.7)$ \\
\hline Papillary carcinoma, NOS & $9(3.5)$ & $8(2.7)$ & $17(3.1)$ & $7(4.3)$ & $4(2.5)$ & $2(2.2)$ & $4(3.0)$ \\
\hline $\begin{array}{l}\text { Squamous cell } \\
\text { carcinoma, NOS }\end{array}$ & $4(1.6)$ & $3(1.0)$ & $7(1.3)$ & $2(1.2)$ & $3(1.9)$ & $1(1.1)$ & $1(0.7)$ \\
\hline Lobular carcinoma, NOS & $1(0.4)$ & $1(0.3)$ & $2(0.4)$ & $2(1.2)$ & $0(0.0)$ & $0(0.0)$ & $0(0.0)$ \\
\hline Carcinoma, NOS & $2(0.8)$ & $0(0.0)$ & $2(0.4)$ & $0(0.0)$ & $0(0.0)$ & $0(0.0)$ & $2(1.5)$ \\
\hline $\begin{array}{l}\text { Carcinoma } \\
\text { undifferentiated, NOS }\end{array}$ & $0(0.0)$ & $1(0.3)$ & $1(0.2)$ & $1(0.6)$ & $0(0.0)$ & $0(0.0)$ & $0(0.0)$ \\
\hline Adenoid cystic carcinoma & $0(0.0)$ & $1(0.3)$ & $1(0.2)$ & $0(0.0)$ & $1(0.6)$ & $0(0.0)$ & $0(0.0)$ \\
\hline $\begin{array}{l}\text { Medullary carcinoma, } \\
\text { NOS }\end{array}$ & $0(0.0)$ & $1(0.3)$ & $1(0.2)$ & $1(0.6)$ & $0(0.0)$ & $0(0.0)$ & $0(0.0)$ \\
\hline
\end{tabular}

${ }^{*}$ Range (minimum value, maximum value).

†Median (IQR).

$\ddagger$ Mean (SD).

NOS, not otherwise specified. 
Table 2 Characteristics of patients with breast cancer according to age at diagnosis in Kelantan, Malaysia ( $\mathrm{n}=549$ )

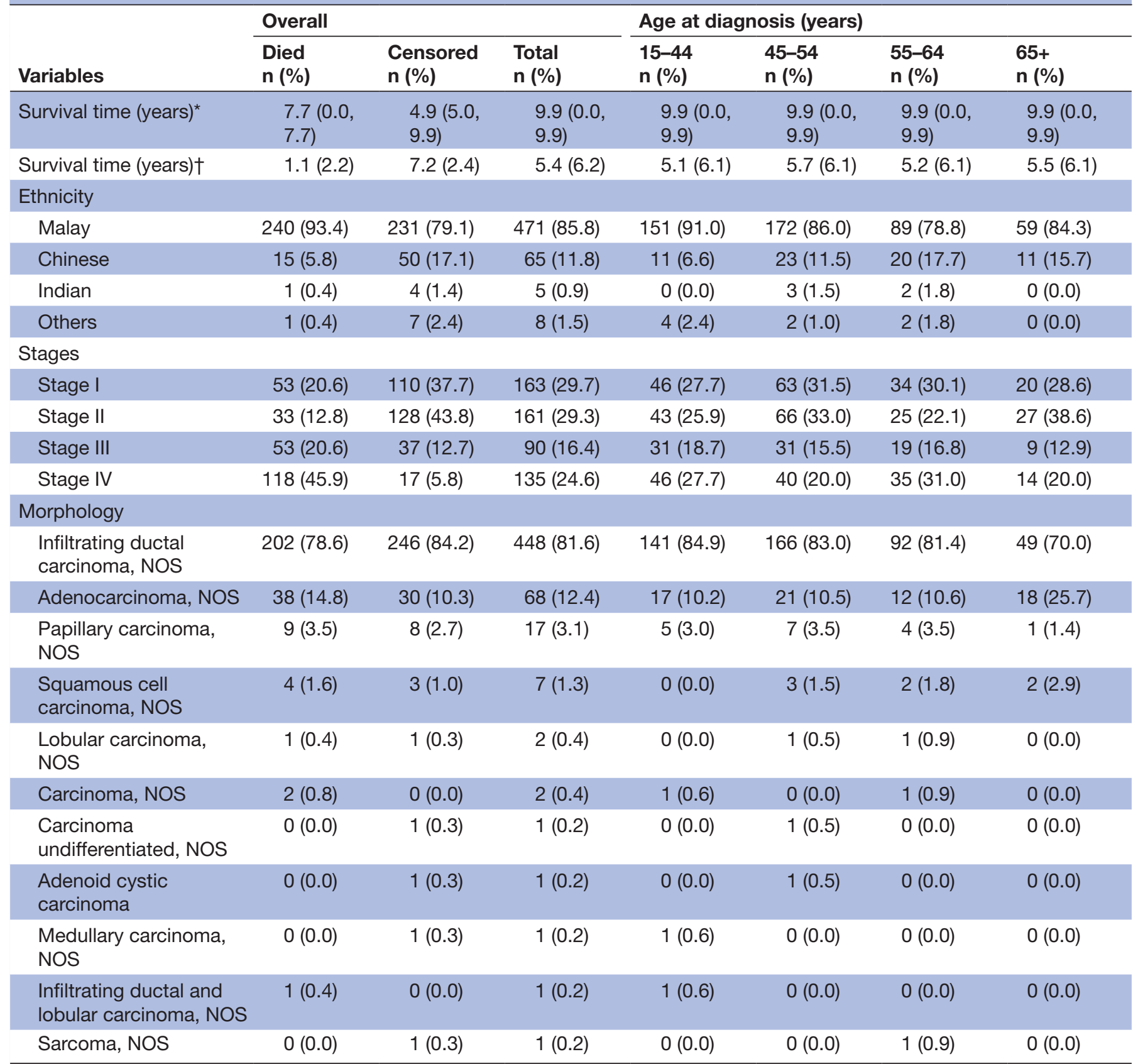

${ }^{*}$ Range (minimum value, maximum value).

†Median (IQR).

NOS, not otherwise specified.

in Kelantan, Malaysia, were 7.7 and 9.9 years for died and censored cases, respectively. Majority of patients with breast cancer in Kelantan, Malaysia were Malay diagnosed with infiltrating ductal carcinoma, not otherwise specified at stage I and stage II aged between 15 and 54 years.

\section{Net survival}

Patients with breast cancer diagnosed at stage IV had the lowest NS overall, followed by stage III patients with breast cancer. The lowest NS was $19.6 \%$ (95\% CI 13.7\% to $27.8 \%$ ) at 5 years following diagnosis in patients with stage IV breast cancer. The highest NS was 93\% (95\% CI $88.9 \%$ to $97.4 \%$ ) at 1 year following diagnosis among patients with stage II breast cancer. Patients with stage I and II breast cancer had the best NS as the survival time increased, and our study showed that there is no significant NS difference among them. Figure 1 shows 1-year, 3-year and 5-year NS of patient with breast cancer diagnosed at each stage. In term of age group, the highest NS was $84.9 \%$ (95\% CI $75.8 \%$ to $95.0 \%$ ) at 1 year following diagnosis among patient with breast cancer aged 65 


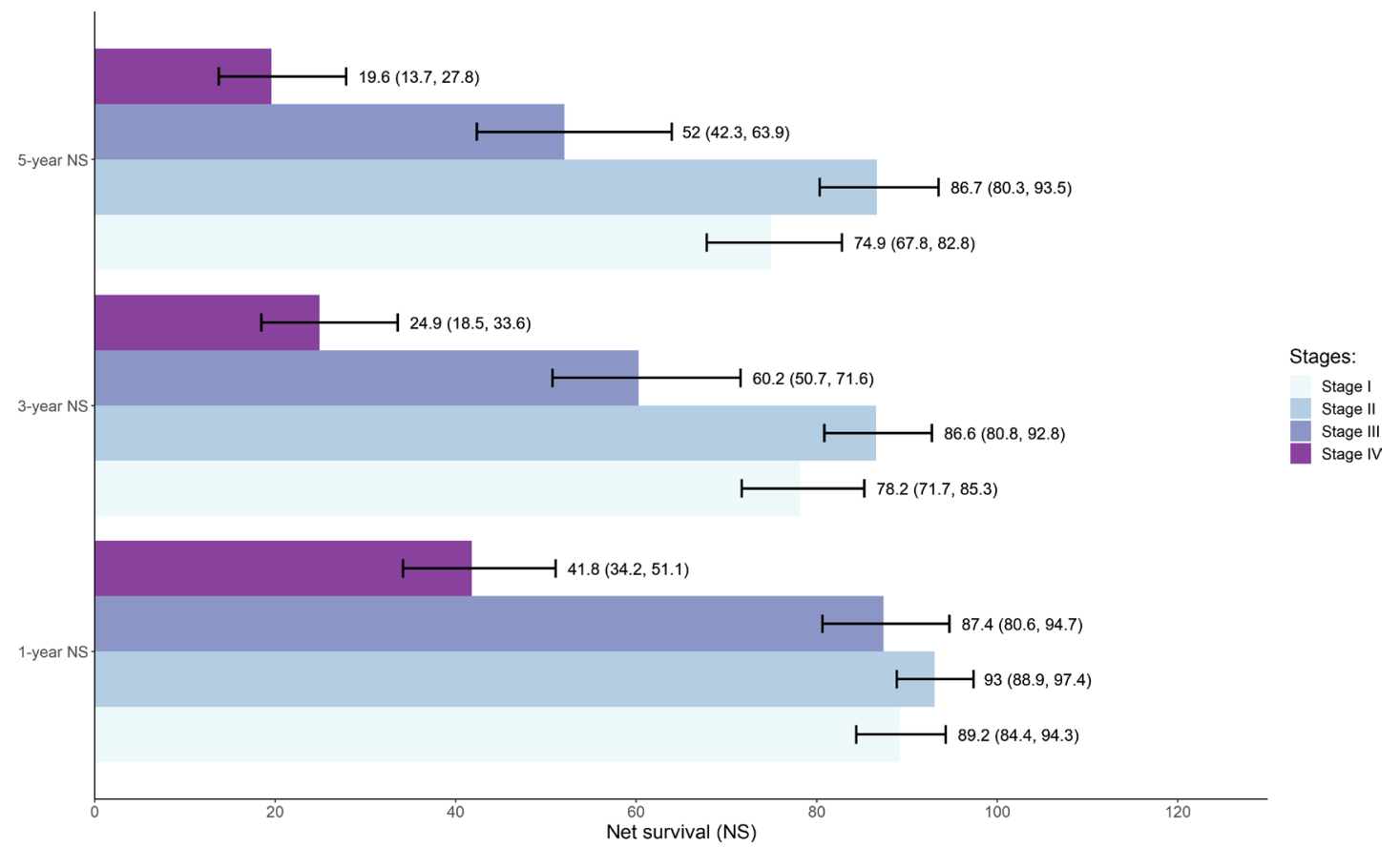

Figure 1 A comparison of NS rates between different breast cancer staging in Kelantan, Malaysia.

and older. The lowest NS was 53.9\% (95\% CI $46.8 \%$ to $62.2 \%)$ at 5 years following diagnosis among those aged 15-44. Figure 2 presents a detail of NS of breast patients in Kelantan, Malaysia for each age group. As the survival time increased, patients with breast cancer diagnosed at aged 65 and older appeared to had better NS compared with other age groups. Additionally, there is no significant NS difference between the remaining three age groups.

\section{DISCUSSION}

The profile of patients with breast cancer in Kelantan, Malaysia was not much different from the profile of breast cancer at the national level in term of age at diagnosis which was 50.6 years at the national level..$^{35}$ Additionally, the majority of the breast cancer cases in Malaysia were Malay which was the same in Kelantan, Malaysia. Most of the patients were diagnosed at stage II $(37 \%)$, followed by stage III $(23 \%)$ at the national level, ${ }^{20}$ while most of the

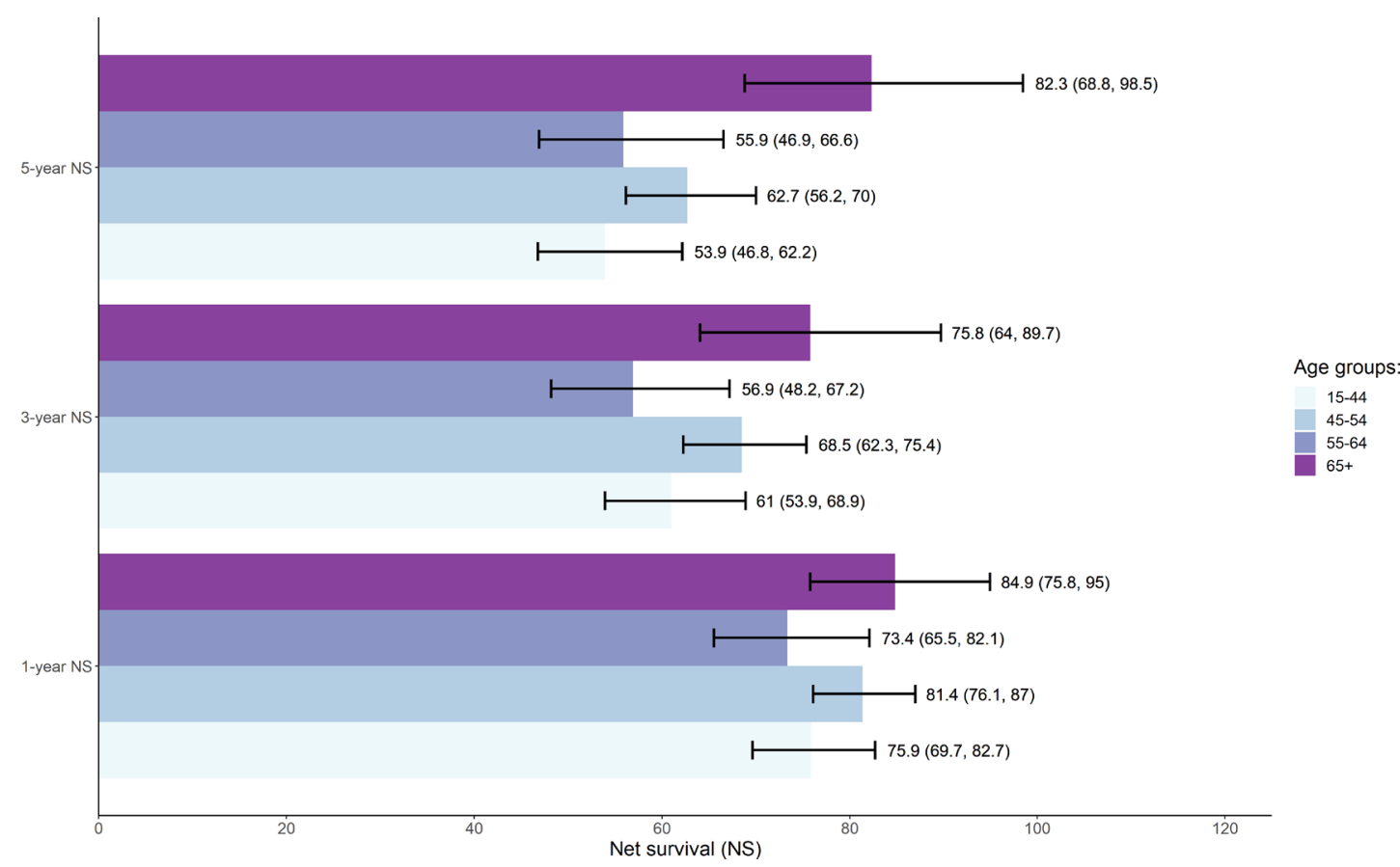

Figure 2 A comparison of NS rates between different age at diagnosis in Kelantan, Malaysia. 
patients in this study were diagnosed at stage I (29.7\%) and stage II (29.3\%). Neighbouring countries such as Singapore had a similar distribution of breast cancer staging to Kelantan, Malaysia in which most of their cases were diagnosed at stage II $(38.5 \%)$ and stage I $(32.7 \%),{ }^{36}$ while Philippines had a similar distribution of breast cancer staging to Malaysia at which about 52\% and 32\% were diagnosed at stage III and stage II, respectively. ${ }^{37}$ About $41 \%$ of breast cancer cases in Kelantan, Malaysia were in late stage, which were stage III and stage IV. These statistics were slightly better than the average statistics in low/middle-income countries in which late-stage cases constituted $50 \%$ of overall breast cancer cases. ${ }^{8}$ Nevertheless, developed countries such as South Korea and Singapore had only $11.8 \%$ and $28.9 \%$ of breast cancer cases in the late stage, respectively. ${ }^{36} 38$

\section{NS according to stage at diagnosis}

In our study, patients with breast cancer diagnosed at stage IV had the poorest survival overall, while those diagnosed at stage I and II had an overall better survival. The NS difference between stages I, II and III was more apparent as the survival time increased. In this study, patients with stage IV breast cancer had a slightly higher proportion of Malay patients and a lower proportion of Chinese patients compared with the other stages. Several studies had shown that Malay patients with breast cancer had a more advanced breast cancer profile and a higher risk of all-cause mortality of breast cancer compared with other Malaysian ethnicities. ${ }^{39} 40$ Additionally, Chinese patients with breast cancer had the highest survival rate compared with other Malaysian ethnicities. ${ }^{11}{ }^{40}$ Another breast cancer survival study in Kelantan, Malaysia using a cause-specific survival approach reported a similar finding in which patients with breast cancer diagnosed at stage II had the lowest hazard of death compared with other stages. ${ }^{12}$ However, the NS at the national level showed a slightly different pattern in which the highest NS was observed among patients with stage I breast cancer, followed by patients with stage II, stage III and stage IV breast cancer. ${ }^{41}$ Neighbouring countries such as Singapore had a similar trend of breast cancer prognosis in term of cancer staging. According to Singapore cancer registry in 2015, a 5-year age-standardised NS of patients with breast cancer was lowest among patients with stage 4 at $23 \%$, followed by stage 3 at $72 \%$, stage 2 at $89 \%$, and stage 1 at $100 \% .{ }^{36}$ Additionally, a study involving 13 population-based registries showed a similar pattern to Singapore, in which the NS is decreasing with increased cancer staging. ${ }^{42}$ This study included cancer registries from Australia, Canada, Denmark, Norway, Sweden and the UK. Overall, the late-stage patients with breast cancer had the poorest survival and the early-stage patients with breast cancer had at he best survival.

\section{NS according to age at diagnosis}

This study found that patients with breast cancer aged 65 and older seemed to had the best survival overall. As shown in figure 2 , as the survival time increased the NS difference between age group 65 and older, and other age groups became more discernible. As explained previously, the NS is a ratio. So, the overall survival of the general population of Kelantan, Malaysia who aged 65 and older is more likely lower, thus resulting in a higher NS for this age group. In term of cancer staging, about $32.9 \%$ of patients with breast cancer in the age group of 65 and older were stages III and IV, while other age groups each had a higher range between $35.5 \%$ and $47.8 \%$ of patients with stage III and IV breast cancer. Late-stage breast cancer was considered as a poor prognostic factor of breast cancer in Malaysia. ${ }^{38} 4344$ Also, several studies had found that patients with breast cancer diagnosed at a younger age presented with a more advanced and severe tumour, thus have lower survival. ${ }^{45-49}$ Hence, this finding is consistent with the result of this study.

South-East Asian countries such as Singapore reported an opposite pattern of survival compared with Kelantan, Malaysia in which the best NS was observed in a younger group of 15-44, while older age group of 75 and older had the lowest survival rate. ${ }^{36}$ However, Japan had a similar finding to Kelantan, Malaysia in which the best 5 -year NS of breast cancer was observed in the older age group of 70-99, while the lowest 5-year NS was observed in the younger age group of $15-34 .{ }^{50}$ Additionally, a study in Iran reported a similar finding in which patients with breast cancer aged between 65 and 74 had the best 5 -year NS out of all age groups. ${ }^{51}$ However, other Asian countries such as South Korea and Japan reported an opposite survival pattern of breast cancer to Kelantan, Malaysia in which the age group of 75 and older had the lowest 5 -year NS. ${ }^{52} 53$ A study in the USA involving patients with breast cancer aged 67 and older had found that patients aged 80-84 had the highest survival, followed by those aged 85 and older. ${ }^{54}$ However, another study done in the USA involving patients with breast cancer aged 65 and older had reported an opposite finding in which the best survival was observed in the age group of $65-74 .{ }^{55}$ Additionally, other western countries such the UK, Netherlands, Australia, Canada, Denmark, Norway and Sweden had reported that the lowest three and 5 years NS was observed among older patients with breast cancer aged 70 and above. ${ }^{42} 5657$ In general, there were conflicting findings regarding the survival of patients with breast cancer diagnosed at older age group. Future studies should explore the impact of age on breast cancer survival. Factors such as socioeconomic status, breast cancer awareness and behaviour among patients with breast cancer in different age groups may provide an insight to these contradicting findings.

The main advantage of this study was the use of Kelantan Cancer Registry, which included all breast cancer cases in Kelantan, Malaysia. Thus, this study was considered as a population-based study. Also, this study used the relative survival approach to explain the NS difference between age groups and stages at diagnosis. This approach has been standard practice in cancer registry studies. However, the main limitation in this study is that 
the Kelantan general population mortality data from the DOSM was only available in an abridged life table format. Thus, the mortality data were expanded by the researcher in this study. Other studies may use a different method to expand the mortality data leading to a lack of standardisation in this research area. Admittedly, the expanded life table remained as an approximation to an actual complete life table. However, the use of different life tables in the relative survival analysis had been shown to have a minor change in the overall estimate of the NS rate. ${ }^{19}$ Currently, the approach used in our study may serve as an alternative for populations without a complete life table. In facts, previous cancer studies had used a similar approach to estimate an NS statistic. ${ }^{58-60}$ Also, this study was restricted by the limited information due to the used of secondary data to further explore the finding of this study. Information such as lymph node involvement, degree of metastasis and hormone receptor status was not available in this study.

\section{CONCLUSIONS}

This study presents the NS difference of patients with breast cancer according to cancer staging and age at diagnosis in the east-coast region of West Malaysia. The best survival was observed among patients with breast cancer aged 65 and older and those diagnosed at stages I and II. The age at diagnosis appeared to had a minimal impact on the NS compared with the stage at diagnosis. The NS is multifactorial in nature, thus detailed sociodemographic and clinical information on the breast cancer profile in this region is needed to extend this finding to other neighbouring populations.

Acknowledgements The publication of this study was supported by the School of Medical Sciences, Universiti Sains Malaysia. Also, the authors would like to thank the Kelantan State Health Department for providing the data in this study.

Contributors TMH: conceptualisation, methodology, formal analysis, writingoriginal draft. NMY: conceptualisation, methodology, writing-review and editing, validation. SMH: methodology, writing-review and editing, validation. SA: validation, supervision.

Funding The authors have not declared a specific grant for this research from any funding agency in the public, commercial or not-for-profit sectors.

Competing interests None declared.

Patient and public involvement Patients and/or the public were not involved in the design, or conduct, or reporting, or dissemination plans of this research.

Patient consent for publication Not required.

Ethics approval This study was carried out in accordance with the Declaration of Helsinki. Ethical approval was obtained from the Human Research Ethics Committee, Universiti Sains Malaysia (USM/JEPeM/18090420), Medical Research and Ethics Committee, Ministry of Health Malaysia (NMRR-18-2675-43980(IIR)) and written approval from the Kelantan State Health Department.

Provenance and peer review Not commissioned; externally peer reviewed.

Data availability statement Data are available on reasonable request. Data may be obtained from a third party and are not publicly available. The General population mortality data for Kelantan is available from eStatistik (https://newss.statistics. gov.my/newss-portalx/ep/epLogin.seam). Additionally, the breast cancer data is available from Non-communicable Disease (NCD) unit, Kelantan State Health Department but this data is not publicly available. However, data is available from theauthors upon reasonable request and with permission of Kelantan StateHealth
Department and Medical Research and Ethics Committee, Ministry ofHealth Malaysia.

Open access This is an open access article distributed in accordance with the Creative Commons Attribution Non Commercial (CC BY-NC 4.0) license, which permits others to distribute, remix, adapt, build upon this work non-commercially, and license their derivative works on different terms, provided the original work is properly cited, appropriate credit is given, any changes made indicated, and the use is non-commercial. See: http://creativecommons.org/licenses/by-nc/4.0/.

\section{ORCID iD}

Tengku Muhammad Hanis http://orcid.org/0000-0003-1466-7765

\section{REFERENCES}

1 Ginsburg O, Bray F, Coleman MP, et al. The global burden of women's cancers: a grand challenge in global health. Lancet 2017;389:847-60.

2 Youlden DR, Cramb SM, Yip CH, et al. Incidence and mortality of female breast cancer in the Asia-Pacific region. Cancer Biol Med 2014;11:101-15.

3 Yip $\mathrm{CH}$, Bhoo Pathy N, Teo SH. A review of breast cancer research in Malaysia. Med J Malaysia 2014;69:8-22.

4 Fan L, Goss PE, Strasser-Weippl K. Current status and future projections of breast cancer in Asia. Breast Care 2015;10:372-8.

5 Kirubakaran R, Chee Jia T, Mahamad Aris N. Awareness of breast cancer among surgical patients in a tertiary hospital in Malaysia. Asian Pac J Cancer Prev 2017;18:115-20.

6 Allemani C, Weir HK, Carreira H, et al. Global surveillance of cancer survival 1995-2009: analysis of individual data for 25,676,887 patients from 279 population-based registries in 67 countries (CONCORD-2). Lancet 2015;385:977-1010.

7 lqbal J, Ginsburg O, Rochon PA, et al. Differences in breast cancer stage at diagnosis and cancer-specific survival by race and ethnicity in the United States. JAMA 2015;313:165-73.

8 Wong FY, Tham WY, Nei WL, et al. Age exerts a continuous effect in the outcomes of Asian breast cancer patients treated with breastconserving therapy. Cancer Commun 2018;38:39-11.

9 Bharat A, Aft RL, Gao F, et al. Patient and tumor characteristics associated with increased mortality in young women ( $<$ or $=40$ years) with breast cancer. J Surg Oncol 2009;100:248-51.

10 Partridge $\mathrm{AH}$, Hughes ME, Warner ET, et al. Subtype-dependent relationship between young age at diagnosis and breast cancer survival. J Clin Oncol 2016;34:3308-14.

11 Ibrahim NI, Dahlui M, Aina EN, et al. Who are the breast cancer survivors in Malaysia? Asian Pac J Cancer Prev 2012;13:2213-8.

12 Nordin N, Yaacob NM, Abdullah NH, et al. Survival time and prognostic factors for breast cancer amongWomen in north-east Peninsular Malaysia. Asian Pac J Cancer Prev 2018;19:497-502.

13 Taib NA, Akmal M, Mohamed I. Improvement in survival of breast cancer patients - trends over two time periods in a single institution in an Asia Pacific country, Malaysia. Asian Pacific J Cancer Prev 2011;12:345-9.

14 Mariotto AB, Noone A-M, Howlader N, et al. Cancer survival: an overview of measures, uses, and interpretation. J Natl Cancer Inst Monogr 2014;2014:145-86.

15 Lambert PC, Dickman PW, Rutherford MJ. Comparison of different approaches to estimating age standardized net survival. BMC Med Res Methodol 2015;15:1-13.

16 UKIACR. Standard operating procedure: guidelines on population based cancer survival analysis, 2016. Available: http://ukiacr.org/ publication/guidelines-population-based-cancer-survival-analysis

17 Sarfati D, Blakely T, Pearce N. Measuring cancer survival in populations: relative survival vs cancer-specific survival. Int $J$ Epidemiol 2010;39:598-610.

18 Eloranta S, Adolfsson J, Lambert PC, et al. How can we make cancer survival statistics more useful for patients and clinicians: an illustration using localized prostate cancer in Sweden. Cancer Causes Control 2013;24:505-15.

19 Schaffar R, Rachet B, Belot A, et al. Estimation of net survival for cancer patients: relative survival setting more robust to some assumption violations than cause-specific setting, a sensitivity analysis on empirical data. Eur J Cancer 2017;72:78-83.

20 National Cancer Intitute. Malaysian National Cancer Registry Report 2007 - 2011. Putrajaya, 2015. http://nci.moh.gov.my

21 Jabatan Perangkaan Malaysia. Jadual Hayat Ringkas, Negeri/Strata Malaysia 2001 - 2009. Putrajaya: Jabatan Perangkaan Malaysia, 2015. https://www.dosm.gov.my 
22 Jabatan Perangkaan Malaysia. Jadual hayat ringkas Malaysia 2010 2013 = abridged life tables Malaysia 2010 - 2013. Putrajaya: Jabatan Perangkaan Malaysia, 2013. https://www.dosm.gov.my

23 Malaysia JP. Jadual Hayat Ringkas Malaysia 2013 -2016. Putrajaya: Jabatan Perangkaan Malaysia, 2016.

24 United Nations. MORTPAK for Windows (Handbook) [POP/SW/ MORTPAK/2003, 2013.

25 R Core Team. R: a language and environment for statistical computing., 2020. Available: https://www.r-project.org/

26 Siran MS, Yusuf MM, Yusoff YS. Expanding Abridge life table by using Heligman Pollard method: Malaysian experience 2010-2013. Int J Bus Soc Sci 2015;6:133-8.

27 Ibrahim RI, Ngataman N, Wan Mohd Abrisam WNA. Forecasting the mortality rates using Lee-Carter model and Heligman-Pollard model. J Phys Conf Ser 2017;890:012128.

28 Ibrahim RI. Expanding an abridged life table using the HeligmanPollard model. Matematika 2008;24:1-10.

29 Dickman PW, Coviello E. Estimating and modeling relative survival. Stata J 2015;15:186-215.

30 Pohar Perme M, Estève J, Rachet B. Analysing populationbased cancer survival - settling the controversies. BMC Cancer 2016;16:1-8.

31 Perme MP, relsurv: relative survival. R Packag. version 2013.

32 Perme MP, Stare J, Estève J. On estimation in relative survival. Biometrics 2012;68:113-20.

33 Perme MP, Pavlic K. Nonparametric relative survival analysis with the $R$ package relsurv. $J$ Stat Softw 2018;87.

34 Roche L, Danieli C, Belot A, et al. Cancer net survival on registry data: use of the new unbiased Pohar-Perme estimator and magnitude of the bias with the classical methods. Int $J$ Cancer 2013;132:2359-69.

35 Abdullah NA, Wan Mahiyuddin WR, Muhammad NA, et al. Survival rate of breast cancer patients in Malaysia: a population-based study. Asian Pac J Cancer Prev 2013:14:4591-4.

36 National Registry of Diseases Office. Singapore cancer registry annual Registry report 2015, 2017. Available: https://www.nrdo.gov. sg/docs/librariesprovider3/Publications-Cancer/cancer-registryannual-report-2015_web.pdf?sfvrsn=10

37 Bhikoo R, Srinivasa S, Yu T-C, et al. Systematic review of breast cancer biology in developing countries (Part 2): Asian subcontinent and South East Asia. Cancers 2011;3:2382-401.

38 Yip C. Improving breast cancer outcomes in Asia. Cancer Contro/2016:50-6 http://www.cancercontrol.info/wp-content/ uploads/2017/12/50-56-YIP.pdf

39 Sung H, Devi CRB, Guida J. Abstract 3414: Ethnic disparities in breast cancer survival in Sarawak, Malaysia. In: AACR 107th annual meeting 2016New Orleans: American Association for Cancer Research, 2016.

40 Bhoo-Pathy N, Hartman M, Yip C-H, et al. Ethnic differences in survival after breast cancer in South East Asia. PLoS One 2012;7:e30995-6.

41 National Cancer Registry Department. Malaysian study on cancer survival (MySCan). Putrajaya, 2018. Available: http://nci.moh.gov.my/ index.php/ms/main-menu-2/laporan

42 Walters S, Maringe C, Butler J, et al. Breast cancer survival and stage at diagnosis in Australia, Canada, Denmark, Norway, Sweden and the UK, 2000-2007: a population-based study. Br J Cancer 2013;108:1195-208.

43 Saxena N, Hartman M, Yip C-H, et al. Does the axillary lymph node ratio have any added prognostic value over $\mathrm{pN}$ staging for South East Asian breast cancer patients? PLoS One 2012;7:e45809.

44 GF H, Taib NA, Pritam Singh RK. What if all patients with breast cancer in Malaysia have access to the best available care: how many deaths are avoidable? Glob J Health Sci 2017;9:32.

45 Kheirelseid EHA, Boggs JME, Curran C, et al. Younger age as a prognostic indicator in breast cancer: a cohort study. BMC Cancer 2011;11:383.

46 Assi HA, Khoury KE, Dbouk H, et al. Epidemiology and prognosis of breast cancer in young women. J Thorac Dis 2013;5:S2-8.

47 McGuire A, Brown JAL, Malone C, et al. Effects of age on the detection and management of breast cancer. Cancers 2015;7:908-29.

48 Tao Z, Shi A, Lu C, et al. Breast cancer: epidemiology and etiology. Cell Biochem Biophys 2015;72:333-8.

49 Chen H-L, Zhou M-Q, Tian W, et al. Effect of age on breast cancer patient prognoses: a population-based study using the SEER 18 database. PLoS One 2016;11:e0165409-11.

50 Yoshimura A, Ito H, Nishino Y, et al. Recent improvement in the longterm survival of breast cancer patients by age and stage in Japan. J Epidemiol 2018;28:420-7.

51 Vostakolaei FA, Broeders MJM, Rostami N, et al. Age at diagnosis and breast cancer survival in Iran. Int $\mathrm{J}$ Breast Cancer 2012;2012:1-8.

52 Zeng $\mathrm{H}$, Chen W, Zheng $\mathrm{R}$, et al. Changing cancer survival in China during 2003-15: a pooled analysis of 17 population-based cancer registries. Lancet Glob Health 2018;6:e555-67.

53 Jung K-W, Won Y-J, Kong H-J, et al. Survival of Korean adult cancer patients by stage at diagnosis, 2006-2010: National cancer registry study. Cancer Res Treat 2013;45:162-71.

54 Schonberg MA, Marcantonio ER, Ngo L, et al. Causes of death and relative survival of older women after a breast cancer diagnosis. $J$ Clin Oncol 2011;29:1570-7.

55 Kanapuru B, Ershler WB, Hesdorffer C, et al. Long-term survival of older breast cancer patients: population-based estimates over three decades. Breast Cancer Res Treat 2012;134:853-7.

56 Ali AMG, Greenberg D, Wishart GC, et al. Patient and tumour characteristics, management, and age-specific survival in women with breast cancer in the East of England. $\mathrm{Br} \mathrm{J}$ Cancer 2011;104:564-70.

57 Bastiaannet E, Portielje JEA, van de Velde CJH, et al. Lack of survival gain for elderly women with breast cancer. Oncologist 2011;16:415-23.

58 Joko-Fru WY, Parkin DM, Borok M, et al. Survival from childhood cancers in eastern Africa: a population-based registry study. Int $J$ Cancer 2018;143:2409-15.

59 Spika D, Bannon F, Bonaventure A, et al. Life tables for global surveillance of cancer survival (the Concord programme): data sources and methods. BMC Cancer 2017;17:159.

60 Joko-Fru WY, Miranda-Filho A, Soerjomataram I, et al. Breast cancer survival in sub-Saharan Africa by age, stage at diagnosis and human development index: a population-based registry study. Int J Cancer 2020;146:1208-18. 